\title{
Urban environmental quality: perceptions and measures in three UK cities
}

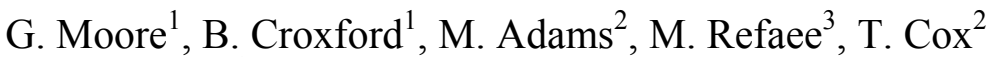 \\ \& S. Sharples ${ }^{3}$ \\ ${ }^{1}$ The Bartlett School of Graduate Studies, University College London, UK \\ ${ }^{2}$ The University of Salford, UK \\ ${ }^{3}$ The School of Architecture, The University of Sheffield, UK
}

\begin{abstract}
The recent promotion of city centre living within UK policy has led to commensurate interest in the quality of the urban environment, particularly the impact and influence that environmental quality has on quality of life and urban sustainability. This paper presents an overview of a study into environmental quality, looking at the environmental conditions and the opinions and experiences of people who live in three of the UK's major cities; London, Sheffield and Manchester. Environmental quality is both subjective and objective in its nature, and it is this combination that is of particular interest to this study. An innovative multi-method approach, combining qualitative and quantitative data collection techniques, has been developed and employed. Environmental monitoring (indoor and outdoor air quality and noise levels) was undertaken alongside participant lead photo-surveys, sound-walks and semistructured interviews with city centre residents. The case studies provide a detailed insight into the components that influence environmental quality; both perceived and measured. The collection and analysis of data has led to the production of 'local environmental quality maps' - spatial representations of local and expert knowledge on urban environmental factors. These maps offer a way to feed different perspectives on environmental issues to decision makers for future policy development. The findings of this study help to understand the influence environmental quality has on quality of life, this in turn can aid urban policy, planning and design. The wider implications of this study to the concept of urban sustainability are also discussed.
\end{abstract}

Keywords: urban environmental quality, subjective \& objective accounts, local environmental quality maps, urban sustainability. 


\section{Introduction}

"The qualities of urban living in the $21^{\text {st }}$ century will define the qualities of civilisation itself" (Harvey [1]).

The quality of the urban environment is of fundamental concern to many. The majority of the world's population live in cities, taking up $2 \%$ of the world's land surface they are homes to over half the world's population, and urbanisation is increasing (Jopling [2] and Pacione [3]). Urban living and working has been promoted in recent UK government policy. Nevertheless problems specific to urban areas exist. Issues such as poor air quality, increased road traffic, social segregation, accessibility to open spaces and socio-economic deprivation are a common occurrence in many urban areas. The prevalence of such issues has led to the formation of initiatives and research agendas aiming to understand the influence environmental quality has on quality of life, and in turn the impact of urban policy, planning and design on the quality of the environment.

Urban environmental quality as a concept is difficult to define; it is multidimensional, multi-faceted and multi-disciplinary in its nature. A useful attempt states; 'environmental quality is the resultant of the quality of composing parts of a given region but yet more than the sum of parts, it is the perception of a location as a whole' (RMB 1996, cited by van Kamp et al. [4]). This definition successfully manages to convey the notion of interaction - the idea that any assessment of the environment requires the integration and exploration of a variety of elements, thus one indicator alone cannot measure environmental quality. At present there is no clear, coherent or consistent system in place to measure or evaluate environmental quality, however many studies have urged for an integrated approach to the subject, incorporating both objective and subjective measures (van Kamp et al. [4] and Marans [5]). Alongside these developments there is a growing body of research examining how different viewpoints can be incorporated into environmental assessment. Many studies have highlighted how 'expert' accounts of physical conditions have conflicted with local people's knowledge and that, rather than local knowledge being inferior or defective, it has proven in some cases more sensitive to local situations (Yearley et al. [6], Forrest and Kearns [7], and Wynne [8]). Indeed, in the context of urban environmental studies, within specific geographical areas, the public may be considered 'local experts' about aspects of their neighbourhood and its conditions. This is emphasised by Bush et al. [9] who states that 'experiences of environmental pollution (referring to air) can vary dramatically at local levels therefore it is particularly important to acknowledge and respond to local knowledge'. The incorporation of local knowledge and multiple viewpoints in research may therefore improve the understanding of certain environmental topics. As van Kamp et al. [4] points out 'objective conditions (alone) do not convey true quality'; echoing the notion to link different forms and types of knowledge in the assessment of urban environmental quality.

This paper presents an overview of a project exploring urban environmental quality within three of the UK's major cities: London, Sheffield and Manchester. 
The aim of the project is to provide a detailed understanding of urban environmental quality, encompassing both the subjective and objective elements. The project can be divided into three key aspects for which data is collected and examined:

-Outdoor environmental quality; the physical environmental conditions in the built environment,

-Perceived environmental quality; the experiences of city dwellers,

-Indoor environmental quality; the physical environmental conditions in a number of residential buildings.

The relationships and interactions between these three aspects are of particular interest to this project. This paper focuses upon the methods developed and employed within this project, alongside how the data gathered can be used to understand the influence of environmental quality on sustainable urban environments. The project forms part of the EPSRC funded 'VivaCity2020: urban sustainability for the 24-hour city' research project (see wWw.vivacity2020.org).

\section{Project methodology}

An innovative multi-method approach combining qualitative and quantitative data collection techniques has been developed and employed in this project. Case studies have been undertaken in three UK city centre areas: London (Clerkenwell), Sheffield (Devonshire Quarter) and Manchester (City Centre). As the project concentrates upon the experiences of city centre living, the areas targeted for study were mixed use areas with housing located near the main daytime and night-time commercial and leisure activities. Within each case study area there are a variety of amenities (shops, offices, entertainment facilities) located within close proximity to residential areas, which themselves are varied, incorporating social housing, privately owned flats and houses. The environmental conditions were also rather varied; with mixed traffic and pedestrian levels and a number of small open spaces within each case study. The project methodology can be divided into three fundamental components linking with the three key aspects of the project: (i) the outdoor environmental monitoring, (ii) the experiences of city centre dwellers, and, (iii) the indoor environmental monitoring.

\subsection{Outdoor environmental monitoring}

The outdoor environmental monitoring involved the intensive monitoring of an urban road system at a number of locations (kerb-side) within each city centre. Noise levels $(\mathrm{dB}(\mathrm{A}))$, carbon monoxide $\left(\mathrm{CO}\right.$, ppm), temperature $\left({ }^{\circ} \mathrm{C}\right)$ and particulate matter (TSP, $\mathrm{PM}_{2.5}$ ) were monitored at a number of sites within the case study areas over a summer and winter period. The monitoring sites were purposely located near the residential premises of participants, to enable comparisons between the data. Other considerations for the location of the monitoring equipment included the practicalities of installation, the threat of 
vandalism and how representative the site was of the surrounding area. The monitoring sites provided a range of conditions (high/low traffic/pedestrians level and mixed land use). A specially designed noise and air quality monitor, the Streetbox (Learian, www.learian.co.uk) was developed and used; a sound level meter has been incorporated into a standard carbon monoxide Streetbox to enable the continuous monitoring of noise and air quality simultaneously (see Croxford and Penn [10] for more information on the Streetbox). A Met One ESampler (light scatter aerosol monitor) was used to monitor the particulate matter. Average temperature, $\mathrm{CO}$ and PM levels were collected at 15-minute intervals, however average noise levels (Leq) were collected at differing intervals (15min, $3 \mathrm{~min}$ or $1 \mathrm{~min})$, depending on the Streetbox used.

\subsection{The experiences of city centre dwellers}

A variety of qualitative methods were utilized in this study to understand residents' experiences of urban environmental quality. Residents from each city were involved in a photo survey, a sound walk and a semi-structured interview. Approximately two weeks before each scheduled interview date a disposable camera (27-exposure, 35mm film, 400 ISO with flash), a log sheet, prepaid envelope and instructions were sent to the participants. Participants were asked to take photographs of their local area, noting the time, date, location and a short description of the photograph on a log-sheet provided. We did not want to be too prescriptive in telling participants what to photograph, so the instructions simply stated: 'we would like you to take photos that record both the positive and negative aspects of your area. Please bear in mind how things sound and smell when taking the photos as well as what they look like'. They were given approximately one week to take photographs before sending the camera back to a researcher in the prepaid envelope provided (the photo-survey). The photographs were then developed and numbered and brought along to the scheduled interview. Prior to the start of the interview participants were asked to complete a short questionnaire (on personal data, household characteristics and local information) and to mark a 5 to 10 -minute walking route around their local area on a map supplied. This walk was undertaken by a researcher and the participant, and recorded with a DAT recorder (the sound-walk). Participants were asked not to talk during the walk, but to listen and observe. On return to the participant's home a semi-structured interview was conducted. The interview was based upon a number of general questions about the urban environment made specific to the resident's locality. Questions were open to interpretation, they included; how would you describe your urban environment? What do you think the air is like outside your home? How would you describe the sound of the area you live in? How would you describe the environmental quality of this area? Participants were also asked to refer to their photographs and to the sound-walk at any stage during the interview. 


\subsection{Indoor environmental monitoring}

The indoor environmental monitoring involved the monitoring of a number of environmental parameters within each participants home. A portable Quest AQ5000Pro monitor was used to monitor levels of carbon dioxide $\left(\mathrm{CO}_{2}\right)$, carbon monoxide $(\mathrm{CO})$ and thermal conditions $\left({ }^{\circ} \mathrm{C}\right)$. A HOBO U12-012 was used to measure light intensity. Respirable-size particle counts ( 0.5 to 5 microns) were determined using a portable laser diode particle counter (Met One model 227A). In addition, noise levels were recorded by using a Quest 2900 Integrating/Logging sound level meter. All equipment was placed in the living room of each home, specifically in the breathing zone of a person sitting on a sofa (approximately $1.5 \mathrm{~m}$ above the floor level) and away from open windows and heat sources. Each participant was asked to complete a daily log sheet, recording certain behaviours (occupancy, smoking, cooking, opening windows) and there approximate time of occurrence. These measurements were taken during a summer and winter period within each home, with data collected for a two-day to one-week period depending on the home monitored.

\section{Data collection and routes of analysis}

A multi-method approach was employed in this study, combining environmental monitoring with participant-led photo-surveys, sound-walks and semi-structured interviews, with the aim to gauge both objective and subjective accounts of urban environmental quality. As a result a vast amount of data has been collected for each case study area. Table 1 presents a summary of the data gathered within each city, showing the multi-faceted set of data over different scales and perspectives, from the individual to area based. The scope of this paper is not analyse the individual components but to see how the whole dataset can be utilised to understand urban environmental quality. As interest lies in exploring the relationship between these accounts a unifying approach to analysis and presentation is deemed necessary.

A spatial analytical framework can be used to examine the data, as all have elements that relate to space. For instance, with the participant led photo-survey the location where each photograph was taken can be mapped. The location of the photographs may indicate how the residents' use and move around their local area, as well as revealing what geographical area they perceive as 'local'. It is also possible to thematically map the photographs by their content and evaluative categories (through information collected via the photo-survey log sheet, devised into coding system) to explore the spatial distribution of certain environmental issues. This is a further dimension to the knowledge produced, leading to an indepth understanding of participants' spatial and social relations. Figure 1 shows the Clerkenwell (London) photo-survey mapped, with each photograph coded into a category that refers to their main content. The photograph locations show a varied and somewhat surprising distribution, scattered across a relatively wide geographical area (much wider than the case study area), with some clustering around main roads or facilities, with groupings of certain issues. 
Table 1: $\quad$ Outline of data collected.

\begin{tabular}{|c|c|c|c|c|c|}
\hline Case Study & $\begin{array}{l}\text { Participant } \\
\text { Interviews }\end{array}$ & $\begin{array}{l}\text { Photo- } \\
\text { surveys }\end{array}$ & $\begin{array}{l}\text { Sound- } \\
\text { walks }\end{array}$ & $\begin{array}{l}\text { Outdoor } \\
\text { monitoring }\end{array}$ & $\begin{array}{l}\text { Indoor } \\
\text { monitoring }\end{array}$ \\
\hline $\begin{array}{l}\text { London } \\
\text { Clerkenwell, } \\
\text { located in the } \\
\text { north east of } \\
\text { the city } \\
\text { centre within } \\
\text { the borough } \\
\text { of Islington }\end{array}$ & $\begin{array}{l}30 \text { semi- } \\
\text { structured } \\
\text { interviews } \\
\text { conducted }\end{array}$ & $\begin{array}{l}680 \text { photos } \\
\text { taken }\end{array}$ & $\begin{array}{l}28 \text { sound- } \\
\text { walks } \\
\text { undertaken }\end{array}$ & $\begin{array}{l}7 \text { kerb-side } \\
\text { locations } \\
\text { monitored } \\
\text { during } \\
\text { winter; } \\
3 \text { kerb-side } \\
\text { locations } \\
\text { monitored } \\
\text { during a } \\
\text { summer } \\
\text { period }\end{array}$ & $\begin{array}{l}30 \text { homes } \\
\text { monitored } \\
\text { during } \\
\text { winter; } 20 \\
\text { repeated for } \\
\text { monitoring } \\
\text { during a } \\
\text { summer } \\
\text { period }\end{array}$ \\
\hline $\begin{array}{l}\text { Sheffield } \\
\text { Devonshire } \\
\text { Quarter, } \\
\text { located to the } \\
\text { west of the } \\
\text { city centre }\end{array}$ & $\begin{array}{l}20 \text { semi- } \\
\text { structured } \\
\text { interviews } \\
\text { conducted }\end{array}$ & $\begin{array}{l}481 \text { photos } \\
\text { taken }\end{array}$ & $\begin{array}{l}11 \text { sound- } \\
\text { walks } \\
\text { undertaken }\end{array}$ & $\begin{array}{l}5 \text { kerb-side } \\
\text { locations } \\
\text { monitored } \\
\text { during } \\
\text { summer; } \\
3 \text { kerb-side } \\
\text { locations } \\
\text { monitored } \\
\text { during } \\
\text { winter }\end{array}$ & $\begin{array}{l}20 \text { homes } \\
\text { monitored } \\
\text { during } \\
\text { summer and } \\
\text { winter }\end{array}$ \\
\hline $\begin{array}{l}\text { Manchester } \\
\text { The city } \\
\text { centre, area } \\
\text { within the } \\
\text { ring road }\end{array}$ & $\begin{array}{l}30 \text { semi- } \\
\text { structured } \\
\text { interviews } \\
\text { conducted }\end{array}$ & $\begin{array}{l}\text { Number of } \\
\text { photos } \\
\text { currently } \\
\text { unconfirmed }\end{array}$ & $\begin{array}{l}29 \text { sound- } \\
\text { walks } \\
\text { undertaken }\end{array}$ & $\begin{array}{l}4 \text { kerb-side } \\
\text { locations } \\
\text { monitored } \\
\text { during a } \\
\text { winter period }\end{array}$ & $\begin{array}{l}30 \text { homes } \\
\text { monitoring } \\
\text { during } \\
\text { winter } \\
\text { (repeated } \\
\text { monitoring } \\
\text { yet to be } \\
\text { undertaken) }\end{array}$ \\
\hline
\end{tabular}

Each part of the data collected can be mapped independently e.g. the environmental monitoring sites, the situational comments within the interview, the sound-walks. Nevertheless, only by linking the individual datasets can we look at the relationships between the different aspects and perspectives of environmental quality. The use of Geographical Information Systems (GIS) as the route of analysis enables the data to be easily combined. The example shown in Figure 2 illustrates how different forms of data (quantitative, qualitative, objective and subjective) can be presented in one arena. This 'local environmental quality map', focusing again on an area within Clerkenwell, incorporates the outdoor pollution monitoring (the black circles and graph), the sound-walks (represented by the thick black lines) and the photographs (the coloured dots and images). The indoor environmental data and the quotes from the semi-structured interviews can be similarly presented in this way, providing spatial representations of local and expert knowledge on urban environmental factors. 
The Sustainable City IV: Urban Regeneration and Sustainability 791

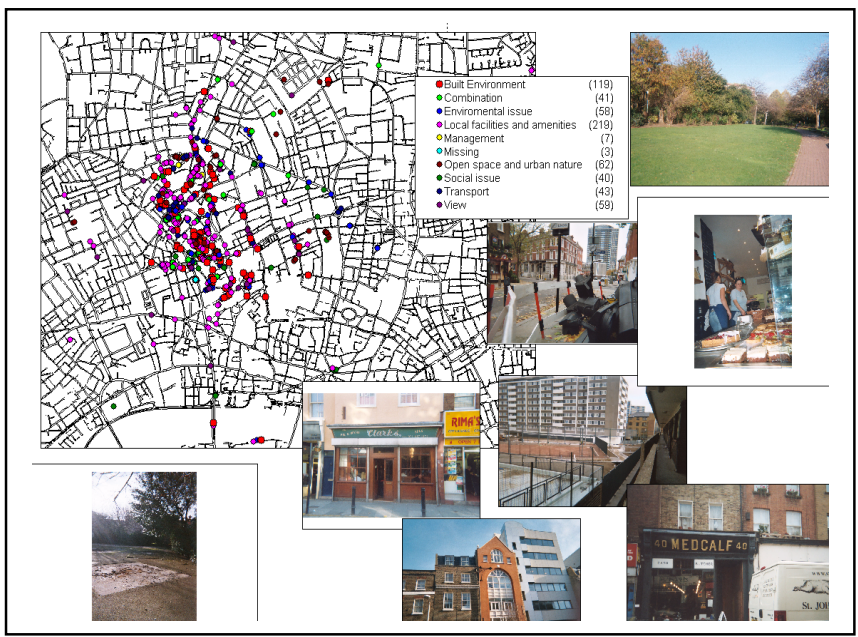

Figure 1: Example of photo-survey mapping.

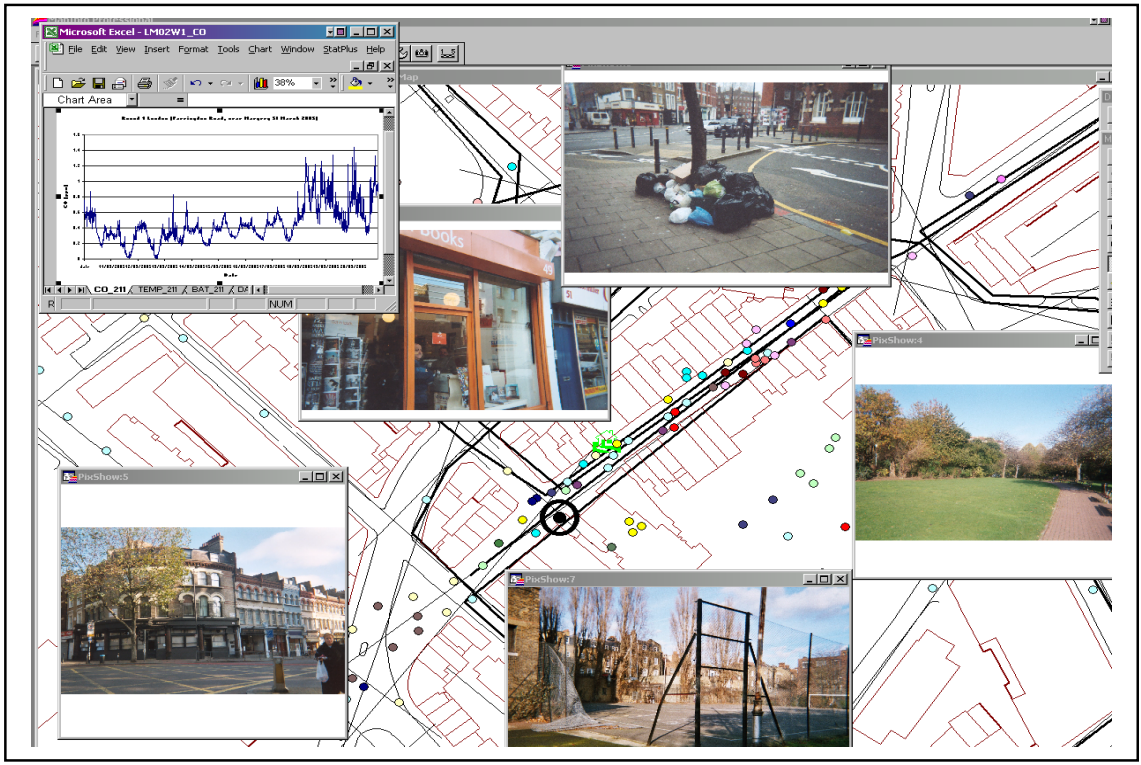

Figure 2: A 'local environmental quality map'. 


\section{Discussion}

The methodology developed and employed within this project was extremely effective for bringing together both subjective and objective aspects of urban environmental quality. The combination of qualitative and quantitative approaches enabled the triangulation of knowledge; for example, by using multiple qualitative methods we were able to successfully tap into residents' experiences of city centre living; their daily, local and sensory experiences. The methods provided the right stimulus for encouraging people to think about how they understand the environment - the photo-survey focused on visual daily encounters, the sound-walk aided people to concentrate on their thoughts and feelings whilst in the built environment, and the semi-structured interview invited people to explain and reflect. Beside this, the monitoring campaigns gave rise to detailed information on the current environmental conditions (and spatial and temporal trends), outside and within participants' homes. The spatial analysis of the data through GIS makes it possible to examine the differences and similarities of these perspectives within each case study area. For instance, the experiences of the people that live in urban areas can supplement the monitored environmental data, providing information on the micro-scale, with details of specific sources and the personal effects of these conditions. Using GIS also gives rise to standardisation for the comparative analysis of each city case study; which will be explored at a later date.

We have developed and used a number of practical tools and techniques for the extraction, presentation and communication of different forms of knowledge (subjective, objective) on urban environmental quality. The methods and processes presented within this paper have a number of implications upon environmental quality research. In particular, there is potential for the method to be used as a tool for residents to highlight and communicate concerns, wishes and positive aspects of their local area to fellow residents or decision makers (e.g. local authorities, planners, policy makers, community organisations). Greater participation in local decision-making is an important ingredient to the sustainability of cities. People have valuable understandings of their local environment that would be beneficial to decision makes if it were adequately tapped into. Thus mechanisms that encourage participation, or make the participatory process more accessible and inclusive, have a valuable role in urban design decision-making. However, it is important to note there are some limitations with the methods. Some aspects of city living and environmental quality may be sensitive (e.g. crime, anti-social behaviour), personal (e.g. family, friends) or non map-able in nature, and therefore not 'captured' or 'represented' easily by these methods. Also, the data collected, like the urban environment itself, is temporal in nature (the environmental conditions and people's feelings change over time); this should be made clear in any outputs generated. These limitations alongside restrictive time scales and budgets may limit widespread use in practice. 


\section{Conclusion}

The quote at the start of this paper by Harvey [1] emphasises the impact urban areas have on civilisation - the urban environment has wider social-cultural reproductions. The complex nature of the urban environment, with its myriad of issues requires an integrated approach across both research and policy to truly understand the processes that are occurring. Multi-disciplinary projects, such as VivaCity2020, give rise to exciting research opportunities, innovations in methodologies and wide-ranging analytical approaches. Within this paper we have presented a project that is exploring environmental issues within 3 UK city centres, through combining different disciplinary approaches. We have found that through combining varying approaches and accounts a comprehensive knowledge base for certain environmental issues can be constructed. There is potential to develop the methods used in this study further; providing tools and techniques to enable and assist communication between city centre residents and professionals about environmental issues, to facilitate the construction of action plans and recommendations for areas, or as even as a way to encourage public participation in research. Future work should develop prospective opportunities to use these techniques in practice, linking with GIS-P (GIS-Participation) studies to aid urban policy, planning and design.

The links between environmental quality and the wider aspects of urban sustainability also needs to be considered. The nature of this study encouraged the participants to openly interpret the concept of 'environmental quality'; through using innovative, non-prescriptive methods we discovered rather sophisticated, complicated views and understandings of the environment, incorporating social, political and economic aspects of the city. This was particularly noticeable in the information gathered by the photo-survey technique, which asked participants to focus upon the positive and negative aspects of their local environment. Participants took photographs of a variety of aspects of the built environment, not just those necessarily 'environmental' in definition. Photographs taken included specific architectural features, favourite pubs, open spaces, friends and family, incidents of litter, and urban management issues. Open, all-embracing interpretations of the quality of the urban environment were clearly demonstrated; this draws attention to the complex nature of environmental quality, emphasising that a holistic approach needs to be taken in future studies, focusing on the wider relationships and connections between the environment, society and the economy.

\section{References}

[1] Harvey, D., Justice, nature and the geography of difference, Blackwell: Oxford, 1996.

[2] Jopling, J., London Pathways to the Future: Thinking Differently, Sustainable London Trust: London, 1999. 
[3] Pacione, M., Urban Environmental Quality and Human Wellbeing - A Social Geographical Perspective, Landscape and Urban Planning, 65, pp. 19-30, 2003.

[4] van Kamp, I., Leidelmeijer, K., Marsman, G. and de Hollander, A., Urban Environmental Quality and Human Well Being Towards a Conceptual Framework and Demarcation of Concepts; a literature study, Landscape and Urban Planning, 65, pp.5-18, 2003.

[5] Marans, R. W., Understanding Environmental Quality through Quality of Life Studies: The 2001 DAS and its Use of Subjective and Objective Indicators, Landscape and Urban Planning, 65, pp. 73-83, 2003.

[6] Yearley, S., Cinderby, S, Forrester, J. Bailey, P. and Rosen, P., Participatory modelling and the local governance of the politics of UK air pollution: A three-city case study, Environmental Values, 12, pp. 247-262, 2003.

[7] Forrest, R. and Kearns, A., Joined up places? Social Cohesion and Neighbourhood Regeneration, York Publishing Services Ltd: York, 1999.

[8] Wynne, B., Misunderstood misunderstandings: social identities and public uptake of science, in Irwin, A. and Wynne, B, eds, Misunderstanding science? The public reconstruction of science and technology, Cambridge University Press: Cambridge, 1996.

[9] Bush, J., Moffatt, S. and Dunn, C.E., Keeping the public informed? Public negotiation of air quality information, Public Understanding of Science, 10 (2), pp. 213-229, 2001.

[10] Croxford, B. and Penn, A., Siting considerations of urban pollution monitors, Atmospheric Environment, 32 (6), pp. 1049-1057, 1998. 